\title{
A cephalometric comparative study of class II correction with Sabbagh Universal Spring (SUS²) and Forsus FRD appliances
}

\author{
Mehmet Oguz Oztoprak' \\ Didem Nalbantgil ${ }^{1}$ \\ Ayhan Uyanlar ${ }^{2}$ \\ Tulin Arun²
}

\section{ABSTRACT}

Objective: The purpose of this clinical prospective study was to compare the dentofacial changes produced by the Sabbagh Universal Spring (SUS ${ }^{2}$ ) and Forsus FRD appliances in late adolescent patients with Class II malocclusion, and quantify them in comparison with an untreated group.

Method: The study was carried out on 59 patients with skeletal and dental Class II malocclusion due to retrognatic mandible. Among these, 20 were treated with SUS², 20 were treated with FRD, and no treatment was done to 19 subjects as the control group. 36 cephalometric landmarks were identified on each lateral cephalometric radiograph.

Results: The effects of both appliances were dentoalveolar and no significant vertical and sagittal skeletal effect on maxilla and mandible was achieved. The retrusion and extrusion of the maxillary incisors as well as the protrusion and intrusion of mandibular incisors were found to be statistically significant in both treatment groups. Soft tissue profile improvement was limited in both treatment groups.

Conclusions: Both appliances corrected Class II discrepancies through dentoalveolar changes; however lower incisor proclination was more prominent with the Forsus FRD. (Eur J Dent 2012;6:302310)

Key words: Sabbagh Universal Spring (SUS2); Forsus FRD; functional therapy; late adolescence

1 Department of Orthodontics, Faculty of Dentistry, Yeditepe University, Istanbul, TURKIYE

2 Private Practice, Istanbul, TURKIYE

- Corresponding author: Dr. Mehmet Oguz Oztoprak Department of Orthodontics, Faculty of Dentistry, Yeditepe University, Bagdat Cad. No: 238, Göztepe, Istanbul 34728, TURKIYE

Tel: +902163636044 Fax:+90 2163636211

Email: ooztoprakahotmail.com

\section{INTRODUCTION}

There are numerous types of functional appliances used for the correction of Class II malocclusion. The selection of the appliance varies according to the type of skeletal and dental anomaly, growth pattern, and the operator's preference. ${ }^{1}$ In 1905 Emil Herbst introduced the first fixed functional appliance that is commonly used for the 
treatment of Class II malocclusion due to mandibular retrognathia or small mandible size., ${ }^{2,3}$ Pancher ${ }^{4}$ then reintroduced the appliance, and reported its favorable effects as a combination of orthopedic and dental corrections. ${ }^{5}$ On the other hand, this appliance has some disavantages such as a great deal of lab work, extensive chair time, breakage in the anchorage unit, and production of rigid forces. ${ }^{6}$ These led the clinicians to seek for new treatment alternatives and appliances.

Sabbagh Universal Spring (SUS2) (Dentaurum, Ispringen, Germanyl is one of these new developed devices, which is the result of the consecutive development of the Sabbagh Universal Spring (SUS) (Figure 1). ${ }^{7}$ SUS was designed as the combination of the most two common appliances, Herbst and Jasper Jumper, aiming to improve their favorable treatment outcome and to minimize their disadvantages. ${ }^{6}$ The subsequently developed SUS ${ }^{2}$ has a telescope unit with a spring for universal intermaxillary use and it produces constant, mainly horizontal forces when the mouth is closed. ${ }^{8}$ The primary advantage of this appliance is that, it acts like Herbst, headgear or Class II elastics according to how it is activated. Also, it is claimed that it helps to avoid extractions and orthognathic operations. ${ }^{6}$

Another newly developed appliance, Forsus Fatigue Resistant Device (FRD) (3M Unitek, Monrovia, CAl (Figure 2) is an innovative semi-rigid three-piece telescoping spring for Class II correction. ${ }^{9}$ It consists of a universal spring module, an ' $L$ ' pin and a pushrod that is available in five different sizes and it is designed to overcome breakage problems that can occur with other fixed function- al appliances. The appliance produces continuous orthopedic forces, and also the force level can be modified by varying the pushrod size to the desired force level depending on the clinical application. This feature gives the oppurtunity to clinicians to modify the force magnitude according to their preference. $^{10}$

The effects of SUS2 appliance, which has a different status from other fixed functional appliances due to its special activation module, have not been documented and compared with any other fixed appliance. The purpose of this clinical study was to compare the dentofacial changes produced by the Sabbagh Universal Spring (SUS2) and Forsus Fatigue Resistant Device (FRD) used in late adolescent patients with Class II malocclusion, and quantifies them in comparison with an untreated control group.

\section{MATERIALS AND METHODS}

The study sample consisted of 59 patients $(40$ treated, 19 untreated) with skeletal and dental Class II malocclusion. All patients were treated in the Yeditepe University clinic with same treatment protocols. The patient selection criteria were as follows: skeletal and dental Class II malocclusion due to mandibular retrognathia, normal or lowangle growth pattern (SN/MP angle was in $25^{\circ}$ $35^{\circ}$ range), postpeak growth period, no extracted or congenitally missing permanent teeth (third molars were not included) and minimum crowding in the lower arch $10-5 \mathrm{~mm}$ crowding was assigned as minimum crowding). Cervical vertebrae maturation index (CVMI) was used for selecting the patients, and CVMI 5 and CVMI 6 stages which cor-
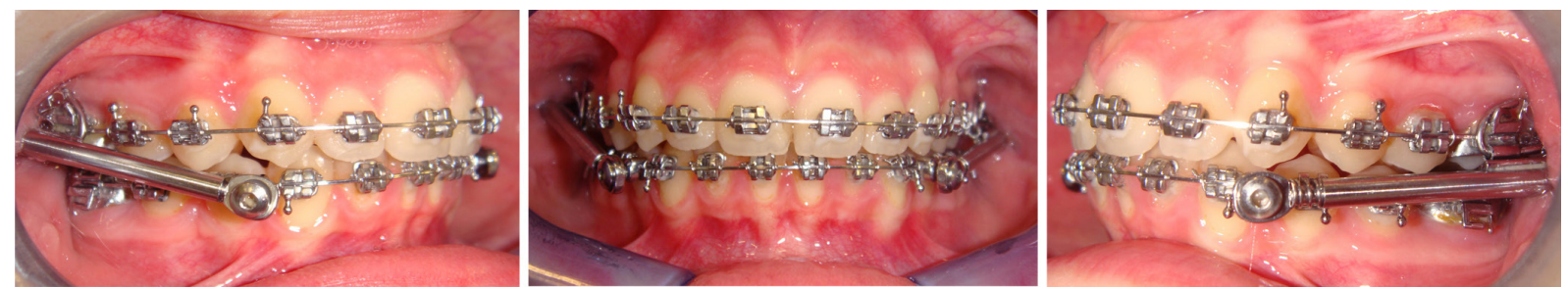

Figure 1. SUS ${ }^{2}$ applied to the headgear tube of the upper first molar and to the lower arch, between the first premolar and the canine in the mouth.
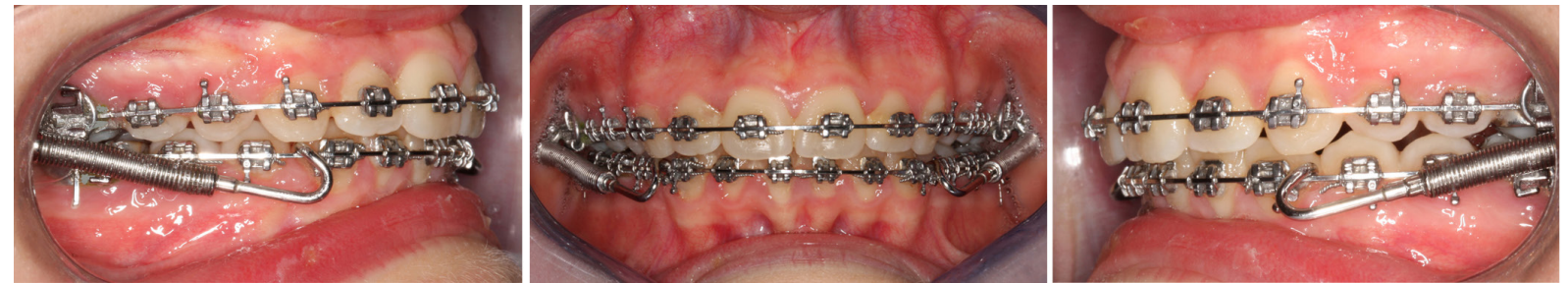

Figure 2. Forsus FRD applied to the headgear tube of the upper first molar and to the lower arch, between the first premolar and the canine in the mouth. 
respond to post-peak growth period was defined by lateral cephalometric radiographs. Approval for the study was obtained from Yeditepe University Ethical Committe.

Growth period was defined with lateral cephalometric radiograms by using cervical vertebrae maturation index for the selection of patients. ${ }^{11}$ The mean pretreatment ages for treatment groups were 15 years 3 months \pm 1 year 2 months in the SUS $^{2}$ group and 15 years 1 month \pm 1 year in the Forsus FRD group. The mean age was 14 years 9 months \pm 1 year 3 months in the control group. The age range and the sex distribution of treatment and control groups are shown in Table 1 and 2 .

To eliminate the effects of growth over the treatment period, an untreated, age-matched Class II control group with skeletal and dental characteristics as similar as possible was obtained from the Faculty of Dentistry Archieve, University of Yeditepe, in department of orthodontics.

\section{Appliance Design andApplication}

In both study groups, same straightwire brackets with a 0.022-inch slot and same prescription were used. Bands were placed with a transpalatal arch in the upper jaw to minimize the anticipated side effects at the upper posterior segment. After the leveling, $0.019 \times 0.025$ inch stainless steel continuous archwires were inserted and cinched back in the upper and lower arches before the insertion of the appliances. No extra torque was given to upper and lower arches. According to the manufacturer's instructions, ${ }^{12}$ the SUS2' s were connected to the headgear tube of the upper first molars and the lower arch between the first premolar and the canine. In order to obtain a rigid telescope effect, the spring force was minimized by inserting and turning the middle telescope tube into the guide tube lunscrew the slotted screw anticlockwise with the activation screwl as described by Sabbagh. ${ }^{6}$ In SUS group the assembled arch adapter was inserted into the lower stainless steel arch between lower 3 and 4 when tightening the hexagonal screw with the hexagon socket screw key. There is no way to use bypass wire.

The patients were seen every 4 weeks and the appliances were activated every eight weeks by a piece of spacer (closed) spring, with steps not exceeding $5 \mathrm{~mm}$.

In the FRD group, the appliance was attached to the maxillary first molar headgear tube with an
$\mathrm{L}$ shaped ball-pin and to the mandibular archwire through a bypass archwire. ${ }^{13}$ FRD consists of a universal spring module, a 'L' pin and a pushrod that is available in five different sizes. The force level can be modified by varying the pushrod size to the desired force level. The first activation was done by inserting wedges on pushrods. Other activations were done by placing pushrods in bigger sizes. The appropriate length of the rod was selected according to the manufacturer's instructions and connected to the lower arch between the first premolar and the canine. The patients were seen every four weeks, and the appliances were activated every eight weeks through wedges placed on the pushrod. In our study, in order to prevent the protrusion of lower anterior segment, bands were placed on second molars and the brackets were fully engaged. The lower arch wire were cinched back to minimize any anchorage loss.

In both groups the appliances were removed when a Class I or overcorrected Class I canine and molar relationship was achieved which eventuated in a mean time of 5 months 5 days \pm 2 months 3 days and 5 months 6 days \pm 1 month 6 days in the SUS ${ }^{2}$ and Forsus FRD groups, respectively.

\section{Cephalometric Methods}

The study was carried out on lateral cephalometric films that were taken before placement and after removal of the SUS ${ }^{2}$ and FRD appliance in both treatment groups and at the beginning and six months after in the control group. The pretreatment and posttreatment cephalograms of each patient were traced manually on acetate paper by one examiner to minimize any method error, and 36 cephalometric landmarks were identified as seen in Table 3 and 4. The reference lines used in this study were also used in previous investigations. ${ }^{14,15}$ To assess the magnitude of the method error, 20 radiographs were selected at random and remeasured one month after the first measurements. The method error was assessed with correlation coefficient. No statistically significant method error was observed.

\section{Statistical Methods}

The pre and post treatment means, and standard deviations between the groups were compared with one-way analysis of variance test. If a statistically significant difference was found, the Tukey multiple comparison test was used to iden- 
tify which groups were different. The differences between the groups were compared with Kruskal Wallis test. If a statistically significant difference was found, the Dunn's multiple comparison test was used to identify which groups were different. To compare the unequal values the chi-square test was used. The level of significance was set at $\mathrm{P}<.05$.

\section{RESULTS}

All patients were corrected to dental Class I relationship in a mean time of 5 months 5 days \pm 2 months 3 days in the SUS ${ }^{2}$ group and 5 months 6 days \pm 1 month 6 days in the Forsus FRD group (Table 1).

No statistically significant differences were found between treatment durations, mean age values and sex distribution of the three groups. (Table 1 and 2)

Pretreatment (T1) comparison of the three groups showed significant differences only in 7 of the 36 variables. (Table 3) SNA and SNB angles were significantly smaller in the Forsus FRD group than in the SUS ${ }^{2}$ and control groups. U1-RL1 distance was higher in Forsus FRD group than in the SUS $^{2}$ and control groups. Overjet, A-labialis superior, E line-labialis superior and inferior linear measurements were significantly smaller in the control group than both treatment groups.

The result of T1 and T2 difference comparison between groups are presented in Table 4. When two treatment groups were compared, increase of the SNA angle and lip strain measurements in Forsus FRD group in contrast to SUS ${ }^{2}$ group and increase of the N-A-Pg and A-labialis superior measurements in SUS2 group in contrast to Forsus FRD group were found significant during treatment. Increase in the IMPA, L1/RL2, SN/OP and L1-NB angles and decrease in the interincisal angle were also more prominent in Forsus FRD group. On the other hand, increase of the $\mathrm{Ar}-\mathrm{Pg}$ measurement of SUS ${ }^{2}$ group was higher than Forsus FRD group. (Table 4)

SN/PP, IMPA, L1/RL2 and SN/OP angles and L1-NB and U1-RL1 linear measurements of SUS2 group showed significant increase when compared with the control group. On the other hand, decrease of U1/SN and U1/RL1 angles and U6$R L 1$, overjet, overbite, labialis superior-RL2 linear measurements were also significant compared with the control group (Table 4).

Comparison of Forsus FRD and control group revealed significant increase of the A-RL1, L1-NB and lip strain linear measurements and IMPA, L1/ $\mathrm{RL} 2, \mathrm{SN} / \mathrm{OP}$ angles and significant decrease in the U1/SN, U1/RL1 and interincisal angles and U6RL1, Labialis superior-RL2, overjet and overbite linear measurements in Forsus FRD group. (Table 4)

\section{DISCUSSION}

The study sample consisted of Class II mandibular retrognathic subjects with normal or low-angle growth pattern and who were at their postpubertal growth period. This group was chosen since they could both benefit from the minimal residual growth and would have minimal relapse due to growth and posttreatment dentoskeletal changes.

The assessment of skeletal age from lateral cephalometric films was performed by the evaluation of maturational stages in the cervical vertebrae in order not to take additional hand-wrist radiograms. . $^{16,17}$

Results indicated that Class II correction occured primarily from the maxillary and mandibular dentoalveolar effects. There were no statistically significant skeletal sagittal changes since the study sample was in post-peak growth period. The comparison of SNA angle confirmed that the SUS2 and FRD appliances had no effect on maxilla at this

Table 1. Mean age and treatment time values of three groups.

\begin{tabular}{lccc}
\hline & SUS $^{2}$ & Forsus FRD & Control \\
\hline Mean Age & 15 year 3 month \pm & 15 year 1 month \pm & 14 year 9 month \pm \\
& 1 year 2 month & 1 year & 1 year 3 month \\
Treatment time & 5 month 5 day \pm & 5 month 6 day \pm & 6 month 1 day \pm \\
& 2 month 3 day & 1 month 6 day & 1 month 5 day \\
\hline
\end{tabular}

Table 2. Gender distribution of three groups.

\begin{tabular}{|c|c|c|c|c|c|c|c|}
\hline & SUS $^{2}$ & & Forsus FRD & & Control & & \\
\hline Male & 9 & $-45,00 \%$ & 8 & $-40,00 \%$ & 5 & $-26,30 \%$ & $x^{2}: 2.7$ \\
\hline Female & 11 & $-55,00 \%$ & 12 & $-60,00 \%$ & 14 & $-73,70 \%$ & $P=.100$ \\
\hline
\end{tabular}


growth period. This finding is in accordance with the results of Weiland and Bantleon ${ }^{18}$ and Karacay et al. ${ }^{19} \mathrm{On}$ the other hand Pancherz ${ }^{5}$ and Valant and Sinclair ${ }^{20}$ stated decrease in SNA angle and inhibition of forward growth of maxilla with Herbst. This contrary finding may be related to varience of the samples' ages and different treatment mechanics.

Likewise maxilla, SUS ${ }^{2}$ and Forsus FRD appliances had no significant effect on the mandible as well. During SUS² therapy, the increase found in

Table 3. Difference in mean changes ( $\mathrm{T} 1$ to $\mathrm{T} 2$ ).

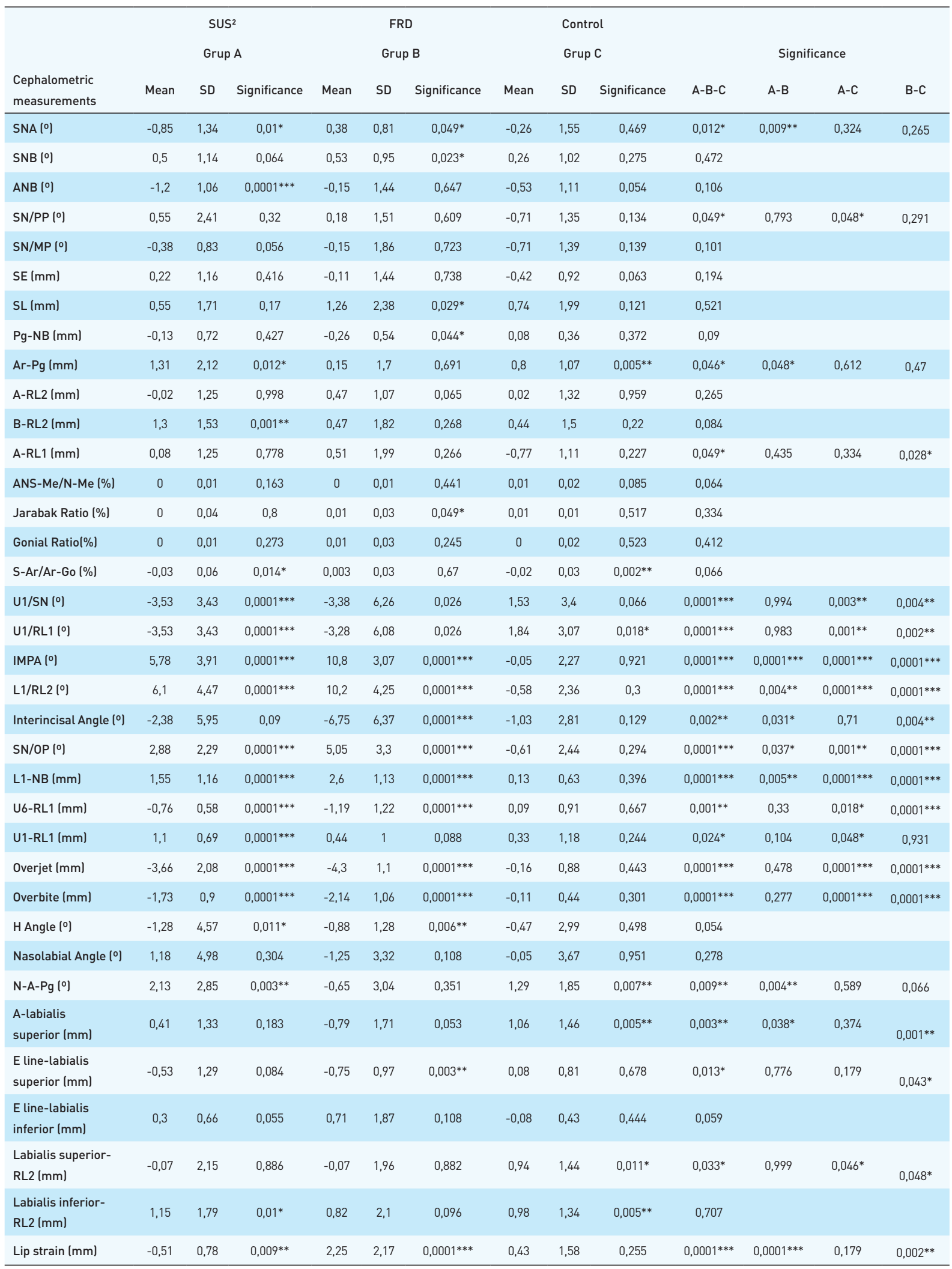

*Significant $(\mathrm{P}<.05),{ }^{* *}$ Significant $(\mathrm{P}<.01), * * *$ Significant $(\mathrm{P}<.001)$ 
Table 4. Changes and comparisons of $\mathrm{T} 1$ and $\mathrm{T} 2$ values within the treatment groups and control group.

\begin{tabular}{|c|c|c|c|c|c|c|c|c|c|c|c|}
\hline \multirow{3}{*}{ Cephalometric measurement } & & \multirow{2}{*}{\multicolumn{2}{|c|}{$\begin{array}{c}\text { SUS }^{2} \\
\text { Group A }\end{array}$}} & \multirow{2}{*}{\multicolumn{2}{|c|}{$\begin{array}{c}\text { FRD } \\
\text { Group B }\end{array}$}} & \multicolumn{2}{|c|}{ Control } & \multirow[b]{3}{*}{$A-B-C$} & \multirow[b]{3}{*}{ A-B } & \multirow{2}{*}{\multicolumn{2}{|c|}{ Significance }} \\
\hline & & & & & & Gro & p C & & & & \\
\hline & & Mean & SD & Mean & SD & Mean & SD & & & $A-C$ & $B-C$ \\
\hline \multirow{2}{*}{ SNA $\left.1^{\circ}\right)$} & T1 & 80,08 & 3,99 & 78,28 & 3,8 & 81,97 & 2,38 & $0,007 * *$ & 0,239 & 0,213 & $0,004^{* *}$ \\
\hline & $\mathrm{T} 2$ & 79,22 & 3,93 & 78,65 & 3,66 & 81,71 & 3,02 & $0,023^{*}$ & 0,867 & 0,084 & $0,026^{*}$ \\
\hline \multirow{2}{*}{ SNB $\left(^{\circ}\right)$} & $\mathrm{T} 1$ & 75,60 & 4,57 & 73,38 & 3,26 & 76,45 & 2,86 & $0,03^{*}$ & 0,14 & 0,75 & $0,029 *$ \\
\hline & $\mathrm{T} 2$ & 76,10 & 4,62 & 73,9 & 3,03 & 76,71 & 2,84 & $0,043^{*}$ & 0,138 & 0,857 & $0,046^{*}$ \\
\hline \multirow{2}{*}{ ANB $\left({ }^{\circ}\right)$} & $\mathrm{T} 1$ & 4,53 & 1,73 & 4,9 & 2,23 & 5,53 & 1,86 & 0,28 & & & \\
\hline & T2 & 3,33 & 1,89 & 4,75 & 1,54 & 5 & 2,59 & $0,027^{*}$ & 0,079 & $0,035^{*}$ & 0,923 \\
\hline \multirow{2}{*}{ SN/PP $\left({ }^{\circ}\right)$} & $\mathrm{T} 1$ & 9,77 & 3,30 & 10,1 & 2,64 & 9,45 & 3,23 & 0,803 & & & \\
\hline & $\mathrm{T} 2$ & 10,33 & 2,95 & 10,28 & 3,05 & 8,74 & 2,19 & 0,138 & & & \\
\hline \multirow{2}{*}{ SN/MP $\left({ }^{\circ}\right)$} & T1 & 32,68 & 6,28 & 31,92 & 4,16 & 30,76 & 3,2 & 0,455 & & & \\
\hline & T2 & 32,30 & 6,35 & 32,07 & 3,94 & 30,05 & 3,29 & 0,275 & & & \\
\hline \multirow{2}{*}{$\mathrm{SE}(\mathrm{mm})$} & $\mathrm{T} 1$ & 20,48 & 2,84 & 20,63 & 2,6 & 20,29 & 3,32 & 0,938 & & & \\
\hline & $\mathrm{T} 2$ & 20,70 & 2,81 & 20,52 & 1,99 & 19,87 & 3,19 & 0,612 & & & \\
\hline \multirow{2}{*}{$\mathrm{SL}(\mathrm{mm})$} & $\mathrm{T} 1$ & 45,77 & 10,67 & 40,63 & 6,56 & 45,43 & 5,72 & 0,085 & & & \\
\hline & $\mathrm{T} 2$ & 46,31 & 10,06 & 41,89 & 6,71 & 46,17 & 5,98 & 0,138 & & & \\
\hline \multirow{2}{*}{$\mathrm{Pg}-\mathrm{NB}(\mathrm{mm})$} & $\mathrm{T} 1$ & 4,28 & 1,72 & 3,35 & 1,44 & 3,03 & 1,99 & 0,071 & & & \\
\hline & $\mathrm{T} 2$ & 4,15 & 1,58 & 3,09 & 1,64 & 3,11 & 1,85 & 0,087 & & & \\
\hline \multirow{2}{*}{$\operatorname{Ar}-\mathrm{Pg}(\mathrm{mm})$} & $\mathrm{T} 1$ & 100,37 & 7,20 & 97,7 & 5,84 & 96,55 & 5,06 & 0,144 & & & \\
\hline & $\mathrm{T} 2$ & 1012,68 & 7,63 & 97,85 & 5,43 & 97,35 & 4,68 & 0,057 & & & \\
\hline \multirow{2}{*}{ A-RL2 (mm) } & $\mathrm{T} 1$ & 64,33 & 5,26 & 62,95 & 5,94 & 64,53 & 3,25 & 0,558 & & & \\
\hline & $\mathrm{T} 2$ & 64,31 & 5,62 & 63,42 & 6,3 & 64,55 & 3,83 & 0,784 & & & \\
\hline \multirow{2}{*}{ B-RL2 (mm) } & $\mathrm{T} 1$ & 55,46 & 8,69 & 52,26 & 7,23 & 55,82 & 4,39 & 0,225 & & & \\
\hline & $\mathrm{T} 2$ & 56,75 & 8,19 & 52,72 & 6,79 & 56,25 & 4,58 & 0,128 & & & \\
\hline \multirow{2}{*}{ A-RL1 (mm) } & $\mathrm{T} 1$ & 48,37 & 4,50 & 47,96 & 2,74 & 46,51 & 2,6 & 0,171 & & & \\
\hline & $\mathrm{T} 2$ & 48,45 & 4,25 & 48,47 & 2,42 & 45,74 & 2,57 & $0,02^{*}$ & 0,995 & $0,042^{*}$ & $0,034^{*}$ \\
\hline \multirow{2}{*}{ ANS-Me/N-Me $[\%]$} & $\mathrm{T} 1$ & 0,54 & 0,03 & 0,56 & 0,02 & 0,54 & 0,02 & 0,188 & & & \\
\hline & $\mathrm{T} 2$ & 0,54 & 0,02 & 0,55 & 0,02 & 0,55 & 0,02 & 0,058 & & & \\
\hline \multirow{2}{*}{ Jarabak Ratio (\%) } & T1 & 0,66 & 0,05 & 0,65 & 0,03 & 0,66 & 0,03 & 0,763 & & & \\
\hline & $\mathrm{T} 2$ & 0,66 & 0,08 & 0,66 & 0,03 & 0,66 & 0,03 & 0,993 & & & \\
\hline \multirow{2}{*}{ Gonial Ratio(\%) } & $\mathrm{T} 1$ & 0,71 & 0,06 & 0,67 & 0,06 & 0,72 & 0,05 & 0,068 & & & \\
\hline & $\mathrm{T} 2$ & 0,71 & 0,06 & 0,68 & 0,05 & 0,72 & 0,05 & 0,066 & & & \\
\hline \multirow{2}{*}{ S-Ar/Ar-Go (\%) } & $\mathrm{T} 1$ & 0,79 & 0,11 & 0,744 & 0,07 & 0,816 & 0,076 & 0,074 & & & \\
\hline & $\mathrm{T} 2$ & 0,76 & 0,11 & 0,747 & 0,072 & 0,792 & 0,079 & 0,331 & & & \\
\hline \multirow{2}{*}{ U1/SN () } & T1 & 104,68 & 5,56 & 102,38 & 6,68 & 100,42 & 7,33 & 0,137 & & & \\
\hline & T2 & 101,15 & 6,92 & 99 & 6,88 & 101,95 & 7,2 & 0,399 & & & \\
\hline & $\mathrm{T} 1$ & 111,68 & 5,56 & 109,53 & 6,65 & 107,32 & 7,32 & 0,124 & & & \\
\hline (1/ & $\mathrm{T} 2$ & 108,15 & 6,92 & 106,25 & 6,67 & 109,16 & 7,12 & 0,414 & & & \\
\hline
\end{tabular}




\begin{tabular}{|c|c|c|c|c|c|c|c|c|c|c|c|}
\hline & & su & & $\mathrm{FI}$ & & Con & & & & & \\
\hline & & Grol & & Gro & & Grol & & & & Significance & \\
\hline Cephalometric measure & & Mean & SD & Mean & SD & Mean & SD & $A-B-C$ & $A-B$ & $A-C$ & $B-C$ \\
\hline IMPA (10) & T1 & 97,98 & 7,13 & 99,9 & 6,97 & 99,11 & 6,63 & 0,678 & & & \\
\hline & T2 & 103,75 & 7,30 & 110,7 & 7,3 & 99,05 & 5,91 & $0,0001^{* * *}$ & $0,006^{* *}$ & 0,093 & $0,0001^{* * *}$ \\
\hline $1 / \mathrm{PI} 210$ & $\mathrm{~T} 1$ & 33,35 & 6,10 & 34,85 & 5,57 & 32,5 & 7,02 & 0,495 & & & \\
\hline & T2 & 39,45 & 5,62 & 45,05 & 4,66 & 31,92 & 6,16 & $0,0001^{* * *}$ & $0,006^{* *}$ & $0,0001^{* * *}$ & $0,0001^{* * *}$ \\
\hline Interincisal Angle $\left({ }^{\circ}\right)$ & $\mathrm{T} 1$ & 125,05 & 7,16 & 125,73 & 7,46 & 130,32 & 7,95 & 0,069 & & & \\
\hline & T2 & 122,68 & 6,21 & 118,98 & 6,89 & 129,29 & 7,47 & $0,0001^{* * *}$ & 0,212 & $0,011^{*}$ & $0,0001^{* * *}$ \\
\hline SN/OP $\left({ }^{\circ}\right)$ & $\mathrm{T} 1$ & 18,15 & 5,32 & 15,05 & 3,24 & 15,32 & 5,35 & 0,081 & & & \\
\hline & T2 & 21,03 & 5,83 & 20,1 & 4,33 & 14,71 & 4,57 & $0,0001 * * *$ & 0,826 & $0,001 * *$ & $0,004^{* *}$ \\
\hline L1-NB $(\mathrm{mm})$ & T1 & 4,86 & 1,69 & 3,91 & 1,89 & 4 & 1,64 & 0,177 & & & \\
\hline & T2 & 6,41 & 1,38 & 6,51 & 1,4 & 4,13 & 1,6 & $0,0001^{* * *}$ & 0,973 & $0,0001^{* * *}$ & $0,0001 * * *$ \\
\hline U6-RL1 (mm) & $\mathrm{T} 1$ & 63,47 & 5,24 & 62,25 & 4,15 & 62,46 & 2,19 & 0,106 & & & \\
\hline & T2 & 62,70 & 5,33 & 64,06 & 3,52 & 62,55 & 2,17 & 0,418 & & & \\
\hline 111-RI $1 / \mathrm{mml}$ & T1 & 70,49 & 4,61 & 71,34 & 3,96 & 67,62 & 2,16 & $0,008^{* *}$ & 0,756 & $0,049 *$ & $0,008^{* *}$ \\
\hline & T2 & 71,60 & 4,67 & 71,78 & 3,98 & 67,94 & 2,59 & $0,004^{* *}$ & 0,988 & $0,013^{*}$ & $0,008^{* *}$ \\
\hline Overjet $(\mathrm{mm})$ & T1 & 5,85 & 1,85 & 5,49 & 1,85 & 3 & 1,51 & $0,0001^{* * *}$ & 0,799 & $0,0001 * * *$ & $0,0001^{* * *}$ \\
\hline & T2 & 2,19 & 0,81 & 1,19 & 1,16 & 2,84 & 1,57 & $0,0001^{* * *}$ & 0,032 & 0,218 & $0,0001^{* * *}$ \\
\hline Overbite $(\mathrm{mm})$ & $\mathrm{T} 1$ & 3,97 & 1,02 & 4,76 & 0,96 & 4,74 & 1,11 & 0,127 & & & \\
\hline & T2 & 2,24 & 0,93 & 2,62 & 0,82 & 4,63 & 1,18 & $0,0001^{* * *}$ & 0,439 & $0,0001^{* * *}$ & $0,0001 * * *$ \\
\hline H Angle $\left({ }^{\circ}\right)$ & $\mathrm{T} 1$ & 12,83 & 4,29 & 12,43 & 4,27 & 10,29 & 4,07 & 0,141 & & & \\
\hline & T2 & 11,55 & 5,07 & 11,55 & 4,35 & 9,82 & 3,96 & 0,389 & & & \\
\hline Nasolabial Angle $\left({ }^{\circ}\right)$ & $\mathrm{T} 1$ & 124,35 & 9,85 & 126,98 & 7,54 & 126,45 & 13,37 & 0,706 & & & \\
\hline & T2 & 125,53 & 9,29 & 125,73 & 6,58 & 126,39 & 13,15 & 0,96 & & & \\
\hline $\mathrm{N}-\mathrm{A}-\mathrm{Pg}\left({ }^{\circ}\right)$ & $\mathrm{T} 1$ & 175,03 & 5,34 & 173,4 & 5,37 & 171,89 & 6,43 & 0,241 & & & \\
\hline & T2 & 177,15 & 5,27 & 172,75 & 4,34 & 173,18 & 7,13 & $0,033^{*}$ & $0,045^{*}$ & 0,083 & 0,969 \\
\hline A-labialis superior & T1 & 22,29 & 3,31 & 22,65 & 2,05 & 19,8 & 1,94 & $0,001^{* *}$ & 0,893 & $0,009 * *$ & $0,002^{* *}$ \\
\hline & T2 & 22,70 & 2,93 & 21,86 & 2,3 & 20,86 & 1,99 & 0,073 & & & \\
\hline E line-labialis superior & $\mathrm{T} 1$ & $-2,95$ & 2,18 & $-2,78$ & 1,6 & $-4,54$ & 1,07 & $0,003^{* *}$ & 0,947 & $0,013^{*}$ & $0,005^{* *}$ \\
\hline & T2 & $-3,47$ & 2,03 & $-3,53$ & 1,89 & $-4,46$ & 1,07 & 0,143 & & & \\
\hline E line-labialis inferior & $\mathrm{T} 1$ & $-1,69$ & 2,76 & $-1,41$ & 2,48 & $-3,4$ & 1,17 & $0,017 *$ & 0,92 & $0,046^{*}$ & $0,022^{*}$ \\
\hline & T2 & $-1,39$ & 2,88 & $-0,71$ & 2,17 & $-3,48$ & 1,26 & $0,001 * *$ & 0,595 & $0,013^{*}$ & $0,001^{* *}$ \\
\hline Labialis superior-RL2 & T1 & 82,42 & 8,55 & 79,1 & 6,69 & 78,51 & 4,41 & 0,16 & & & \\
\hline & T2 & 82,35 & 7,86 & 79,04 & 7,15 & 79,45 & 4,91 & 0,253 & & & \\
\hline Labialis inferior-RL2 & T1 & 75,92 & 8,64 & 72,68 & 9,24 & 74,68 & 4,16 & 0,416 & & & \\
\hline & T2 & 77,07 & 7,97 & 73,51 & 10,16 & 75,66 & 4,13 & 0,362 & & & \\
\hline Lip strain (mm) & $\mathrm{T} 1$ & $-3,33$ & 2,38 & $-3,2$ & 2,42 & $-1,62$ & 3,22 & 0,098 & & & \\
\hline & T2 & $-3,84$ & 2,44 & $-0,95$ & 1,58 & $-1,19$ & 3,32 & $0,001 * *$ & $0,002^{* *}$ & $0,005^{* *}$ & 0,954 \\
\hline
\end{tabular}

T1: Pretreatment

T2: Posttreatment 
the $\mathrm{Ar}-\mathrm{Pg}$ distance may be related to the anterior repositioning of the mandible rather than forward growth. Küçükkeleș et $\mathrm{al}^{21}$ reported that the reason for the increase might be due to the change in the pogonion location whereas; Chen et al ${ }^{22}$ proclaimed the reason for this increase as the backward and upward relocation of articulare point during functional therapy.

There were no statistically significant vertical changes related to the appliance wear. This finding confirmed that the appliance did not change the facial height in late adolescent patients and it is consistent with the findings of Weiland and Bantleon, ${ }^{18}$ Covell et al, ${ }^{23}$ Pancherz, ${ }^{5}$ Küçükkeleș and Orgun, ${ }^{24}$ and Nalbantgil et al. ${ }^{25}$

The correction of Class II malocclusion by both appliances was achieved by dentoalveolar changes. This study found no significant difference in the upper incisor retroclination (U1/SN) between the SUS² and Forsus FRD groups. Both treatment groups demonstrated significant decrease in the interincisal angle, which was related to upper incisor retrusion and lower incisor protrusion; however, decrease was more prominent in the Forsus FRD group. Likewise, the significant greater reduction in overjet and overbite in the Forsus FRD group was related to the upper incisors' retroclination and lower incisors' proclination.

As for the lower incisors, the anterior tipping was apparent in both appliances (IMPA, Forsus FRD: $10.8 \pm 3.07^{\circ}$; SUS $^{2}: 5.78 \pm 3.91^{\circ}$ J. The change in the parameters related to mandibular incisors indicated that these teeth intruded with labial tipping. Besides using negative torqued lower incisor brackets or having lingual crown torque at the lower anterior segment, full ligation of the lower dental arch and reducing the force setting are possible options to prevent the protrusion of the lower incisors.

The clockwise rotation of the occlusal plane was produced by the intrusion of upper molars due to the highpull headgear effect of the appliances acting on the maxillary molar area. Since the dentition was blocked together, this force also influenced the maxillary incisors through archwire. The increase in SN-OP angle is also related with the protrusion and intrusion of the lower incisors in the mandible. Thus, the intrusive force acting on the upper molars also acts on the anterior lower dentition that was found more prominent in For- sus FRD therapy. The proclination of the lower incisors was the result of the intrusive force as well as anchorage loss. The use of lower incisor brackets with negative torque values or lingual crown torque at the lower anterior segment may prevent this protrusion.

The changes related to the soft-tissue profile were to a lesser extent than the dentoalveolar changes. In SUS² group an increase was found in $\mathrm{N}-\mathrm{A}-\mathrm{Pg}$ angle; however, changes were insignificant when compared with the control group. This finding should be related to the forward movement of soft tissue pogonion and backward movement of a point. On the other hand, Weiland and Drocshl, ${ }^{26}$ Lange et $\mathrm{al}^{27}$ and Ruf and Pancherz ${ }^{28}$ stated in their studies that the facial convexity improved with functional appliances. This difference may be related to varience of growth period and different types of appliances that had been used. The slight decrease in $E$ line-labialis superior and Labialis superior-RL2 measurements occurred as a result of the retrusion of the upper lip following the backward tipping of the upper incisors and also, the lower lip was no longer captured behind the upper incisors. Similar soft-tissue changes were attained from previous studies. ${ }^{24,25}$ No statistically significant changes were observed in lower lip position with SUS² and Forsus FRD, when compared with control group.

\section{CONCLUSIONS}

Dentofacial and soft tissue changes in late adolescent Class II malocclusion patients attained with SUS ${ }^{2}$ and Forsus FRD appliances were as follows:

- In the SUS² and Forsus FRD groups, no statistically significant vertical and sagittal skeletal effect on the maxilla and the mandible were present. Since no vertical changes were observed, the appliances can be used in high angle patients without gummy smile.

- In both study groups, the changes that took place in post peak growth period were achieved by only dentoalveolar changes. Thus, these appliances can be an acceptable substitute to Class II elastics for patients who appear to be noncompliant.

- In study groups, upper incisor retrusion and extrusion and lower incisor protrusion and intrusion were observed. SUS ${ }^{2}$ group demonstrated lesser lower incisor protrusion and upper molar 
intrusion when compared with Forsus FRD group.

- The changes related to the soft tissue profile were limited, so both appliances may not compensate the esthetic facial outcome that can be achieved by orthognathic surgery in Class II adult patients.

\section{REFERENCES}

1. Schmuth GPF. Milestones in the development and practical application of functional appliances. Am J Orthod Dentofacial Orthop 1983;84:48-53.

2. Herbst E. Atlas und Grundriss der Zahnarztlichen Orthpadie. Munich: J.F. Lehmann Verlag. 1910.

3. Aelbers CMF, Dermaut LR. Orthopadie in der OrthodontieEin Literaturüberblick. Inf Orthod Kieferorthop 1999;31:6579.

4. Pancherz H. Treatment of class II malocclusions by jumping the bite with the Herbst appliance. A cephalometric investigation. Am J Orthod 1979;76:423-442.

5. Pancherz $\mathrm{H}$. The mechanism of Class II correction in Herbst appliance treatment. Am J Orthod Dentofac Orthop 1982;82:104-113.

6. Sabbagh A. The Sabbagh Universal Spring. In the: Papadopoulos MA. Orthodontic treatment of the Class II noncompliant patient. Mosby. 2006:203-16.

7. Now even beter to reach Class I. SUS²- Sabbagh Universal Spring. http://www.dentaurum.de/eng/orthodontie_4138_7287.aspx, 14.9.2005.

8. http://www.dentaurum.de/files/989-543-20.pdf

9. Heinig N, Goz G. Clinical application and effects of the Forsus spring. A study of a new Herbst hybrid. J Orofac Orthop 2001;62:436-450.

10. El-Sheikh MM, Godfrey K, Manosudprasit M, Viwattanatipa $\mathrm{N}$. Force deflection characteristics of the fatigue-resistant device spring: an in vitro study. World J Orthod 2007;8:3036.

11. Hassel B, Farman A. Skeletal maturation evaluation using cervical vertebrae. Am J Orthod Dentofacial Orthop 1995; 107:58-66.

12. http://www.dentaurum.de/files/989-539-00.pdf.

13. Sabbagh A. Classification of the noncompliance appliances used for Class II correction. In the: Papadopoulos MA. Orthodontic treatment of the Class II noncompliant patient. Mosby. 2006:9-34.

14. Firouz M, Zernik J, Nanda R. Dental and orthopedic effects of high pull headgear in treatment of Class II division 1 malocclusion. Am J Orthod Dentofacial Orthop 1992;102:197205.
15. Talass MF, Talass L, Baker RC. Soft tissue profile changes resulting from retraction of maxillary incisor. Am J Orthod Dentofacial Orthop. 1987;91:385-394.

16. Lamparski DG. Skeletal age assessment utilizing cervical vertebrae (dissertation). Pittsburg, PA: The University of Pittsburg. 1972.

17. O' Reilly M, Yanniello GJ. Mandibular growth changes and maturation of cervical vertebrae-a longitudinal cephalometric study. Angle Orthod 1988;58:179-184.

18. Weiland FJ, Bantleon HP. Treatment of class II malocclusions with the Jasper Jumper appliance-a preliminary report. Am J Orthod Dentofac Orthop 1995;108:341-350.

19. Karacay S, Akın E, Olmez H, Gurton AU, Sagdıc D. Forsus Nitinol Flat Spring and Jasper Jumper corrections of Class II division 1 maloclusions. Angle Orthod 2006;76:666-672.

20. Valant JR, Sinclair PM. Treatment effect of the Herbst appliance. Am J Orthod Dentofac Orthop 1989;95:138-147.

21. Küçükkeleș N, İthan I, Orgun A. Treatment Efficiency in Skeletal Class II Patients Treated with the Jasper Jumper. Angle Orthod 2007;77:449-56.

22. Chen JY, Will LA, Niederman R. Analysis of efficacy of functional appliances on mandibular growth. Am J Orthod Dentofac Orthop 2002;122:470-476.

23. Covell DA, Trammell DW, Boero RP, West R. A cephalometric study of Class II division 1 malocclusion treated with the Jasper Jumper appliance. Angle Orthod 1999;69:311-320.

24. Küçükkeleș N, Orgun A. Correction of Class II malocclusions with a Jasper Jumper in growing patients. Eur $J$ Orthod 1995; 17:445.

25. Nalbantgil D, Arun T, Sayınsu K, Ișık F. Skeletal, Dental and Soft Tissue Changes induced by the Jasper Jumper appliance in late adolescence. Angle Orthod 2005;75;426-436.

26. Weiland FJ, Droschl H. Treatment of a Class II, Division 1 malocclusion with the Jasper Jumper: a case report. $\mathrm{Am} \mathrm{J}$ Orthod Dentofac Orthop 1996;109:1-7.

27. Lange DW, Kalra V, Broadbent BH, Powers m, Nelson S. Changes in soft tissue profile following treatment with the bionator. Angle Orthod 1995;6:423-430.

28. Ruf S, Pancherz H. Dentoskeletal effects and facial profile changes in young adults treated with the Herbst appliance. Angle Orthod 1998;69:239-246. 